\title{
O saber docente e a formação profissional: a relação entre o saber cotidiano e escolar no ensino e aprendizagem de matemática na educação básica
}

\author{
Teaching knowledge and vocational training: the importance of the relationship between daily \\ knowledge and school knowledge in teaching and mathematical learning in basic education \\ Saber docente y formación profesional: la importancia de la relación entre el saber cotidiano y el \\ saber escolar en la enseñanza y el aprendizaje matemático en la educación básica
}

\section{Resumo}

O presente estudo é resultado de uma investigação que estudou os saberes docentes e a formação de professores, dando ênfase para a importância da relação entre saber cotidiano e saber escolar no ensino e na aprendizagem da Matemática. Teve como objetivo investigar se a formação profissional tem auxiliado o docente na relação entre o saber cotidiano e o saber escolar no processo de ensinar e aprender matemática. Tomamos como referencial teórico os estudos de Freire (1996), Lorenzato (2010), Gauthier (1998), Ribeiro (1997), Franchi (1995), Nogueira et al. (2014), Andrade (2013) e PCNs de Matemática (Brasil, 1998). Utilizamos da pesquisa bibliográfica, apropriando-se de métodos qualitativos com análise e discussão, apoiando-se em leitura, reflexão e diálogo. Os resultados mostram que a formação profissional de professores pouco contribui em formar docentes capazes de identificar a realidade em que o aluno está inserido, portanto, um grande desafio de ser docente está na prática de relacionar os conteúdos escolares com a realidade do educando, constatando-se que o ensino da matemática para ser mais efetivo tem a necessidade de considerarem a importância da relação entre os conteúdos das diferentes disciplinas escolares e a realidade e interesse dos alunos, pois seus conteúdos, quando abordados de forma isolada, não se tornam uma ferramenta eficaz para resolver problemas e para a construção de novos conceitos. Assim, a relação do saber escolar com o saber cotidiano se torna não só importante, mas necessário para o ensino e aprendizagem.

Palavras-chave: Formação de professores; Relação de saberes; Ensino aprendizagem em matemática.

\section{Abstract}

The study is the result of an investigation into teaching knowledge and the training of teachers in the teaching of mathematics, present for the importance of the relationship between everyday knowledge and school knowledge in 
and in the learning of mathematics. It aimed to investigate whether professional training can help the teacher in the relationship between everyday knowledge and school knowledge in the process of teaching and learning mathematics. We take as theoretical reference the studies of Freire (1996), Lorenzato (2010), Gauthier (1998), Ribeiro (1997), Franchi (1995), Nogueira et al. (2014), Andrade (2013) and PCNs of Mathematics (Brasil, 1998). We used bibliographic research, appropriating qualitative methods with analysis and discussion, relying on reading, reflection and dialogue. The results show that teachers who educated little in forming the challenge of qualified teachers for the student of reality are inserted, therefore, a great educator is in the practice of including school contents with reality, finding himself as a teacher to be a teacher if that mathematics education, in order to be more effective, takes into account the importance of the discipline and the contents of the reality and interest of the students, since its contents, I teach teaching in an individualized way, do not become an effective tool for solving problems and for the construction of new concepts. Thus, the relationship between school knowledge and everyday knowledge becomes not so important, but necessary for teaching and learning.

Keywords: Teacher training; Relation of knowledge; Teaching learning in mathematics.

\section{Resumen}

El estudio es el resultado de una investigación sobre la enseñanza del saber y la formación de profesores en la enseñanza de las matemáticas, presente por la importancia de la relación entre el saber cotidiano y el saber escolar en y en el aprendizaje de las matemáticas. Tuvo como objetivo investigar si la formación profesional puede auxiliar al docente en la relación entre el saber cotidiano y el saber escolar en el proceso de enseñanza y aprendizaje de las matemáticas. Tomamos como referencia teórica los estudios de Freire (1996), Lorenzato (2010), Gauthier (1998), Ribeiro (1997), Franchi (1995), Nogueira et al. (2014), Andrade (2013) y PCNs de Matemáticas (Brasil, 1998). Utilizamos la investigación bibliográfica, apropiándonos de métodos cualitativos con análisis y discusión, apoyándonos en la lectura, la reflexión y el diálogo. Los resultados muestran que se insertan docentes que educaron poco en formar el desafío de docentes capacitados para el alumno de la realidad, por lo tanto, un gran educador está en la práctica de incluir los contenidos escolares con la realidad, encontrándose como docente para ser docente si eso La educación matemática, para ser más eficaz, tiene en cuenta la importancia de la disciplina y los contenidos de la realidad e interés de los alumnos, ya que sus contenidos, que enseño la enseñanza de forma individualizada, no se convierten en una herramienta eficaz para la resolución de problemas. problemas y para la construcción de nuevos conceptos. Así, la relación del saber escolar con el saber cotidiano se torna no tan importante, pero sí necesaria para la enseñanza y el aprendizaje.

Palabras clave: Formación de profesores; Relación de saberes; Enseñanza aprendizaje en matemáticas.

\section{Introdução}

O saber docente fundamenta o ato de ensinar e aprender, que deve ser tratado em um sentido amplo e a formação profissional deve ser considerada como imprescindível e uma das fontes das quais originam-se os saberes dos professores. Este saber que pode ser adquirido da experiência constitui um fundamento da prática e da competência docente.

Nessa lógica, o saber do professor se atribui a um sentido amplo, que engloba os conhecimentos, as competências, as habilidades ou aptidões e as atitudes dos docentes. Tardif (2002, p. 36) define saber docente como "um saber plural, formado pelo amálgama, mais ou menos coerente, de saberes oriundos da formação profissional e de saberes disciplinares, curriculares e experienciais". O autor concebe "os saberes docentes" como um conjunto de saberes que fundamentam a prática docente. Para Charlot (2000, p. 62) "não é o saber que é prático, mas, sim, o uso dele, em uma relação prática com o mundo".

Os autores destacam que a extensão e o domínio do saber docente abrangem, além do conhecimento específico da área, o saber da ciência da educação e da própria prática docente. Compreende-se, então, que os saberes docentes se relacionam necessariamente à profissionalização docente. Profissão essa que não é neutra, como afirma Cunha (2005), e, se não neutra, precisa estar munida de conceitos e práticas voltados para a formação de um sujeito capaz de interagir e transformar o mundo.

Diante do exposto indagou-se: Como a formação profissional pode auxiliar no tratamento da relação ente o Saber Cotidiano e o Saber Escolar no ensino e na aprendizagem da Matemática, tendo em vista a importância destes saberes para a produção de conhecimento no processo educativo da educação básica?

O tema estudado foi oportuno, pois trouxe para a discussão a importância de relacionar o saber cotidiano com o saber escolar no ensino da Matemática na Educação Básica. Tal discussão tem grande relevância não só para a comunidade escolar, 
mas para a comunidade em geral, pois é sabido que a Matemática está presente no cotidiano do aluno. Assim, quando o aluno chega à escola já traz consigo algum saber matemático, o qual foi adquirido através de sua vivência em um contexto histórico, cultural e religioso. E esse saber, que é adquirido no seio familiar, não é imposto e sim descoberto pelo próprio sujeito, e, muitas vezes não é reconhecido pelos próprios docentes.

Neste contexto, este trabalho objetivou evidenciar se a formação profissional tem auxiliado o docente na relação entre o saber cotidiano e o saber escolar no processo de ensinar e aprender matemática. E, assim, surgiu uma inquietação que motivou a busca de informações a respeito das práticas pedagógicas do professor de matemática e, assim, possibilitá-lo de fazer uma reflexão sobre o uso de metodologia de ensino e aprendizagem baseada no cotidiano do aluno, pois, "os saberes da experiência podem ser melhorados, em qualidade e quantidade, se o professor se habilitar a refletir sobre sua prática docente" (Lorenzato, 2010, p. 11). Assim poderá transformar a educação, ao invés de impor o conteúdo, apenas facilitar a partir da realidade de cada um para que os mesmos possam ser protagonistas da sua própria aprendizagem tornando-se cidadãos críticos, criativos e éticos.

No que concerne à estrutura deste trabalho, o mesmo está organizado da seguinte maneira: inicialmente é introduzido e logo são apresentados alguns pressupostos teóricos para falar da relevância do elo entre os conteúdos matemáticos e o conhecimento prévio do aluno como condição para uma aprendizagem significativa, em seguida aborda-se a formação profissional e os desafios de ser docente, sendo uma vertente muito importante para a promoção de práticas educativas integradas às várias culturas existentes. Por conseguinte, discute-se sobre a importância da relação entre o saber escolar e o saber cotidiano para o ensino e aprendizagem em Matemática; no próximo tópico, apresenta-se algumas contribuições para o ensino e aprendizagem em Matemática, seguido da metodologia a qual desenvolveu-se este trabalho e, por fim, são apresentadas as Considerações Finais.

\section{Metodologia}

O presente artigo trata-se de uma pesquisa bibliográfica que, de acordo com Silva e Schappo (2002), consiste na procura de referências teóricas publicadas em livros, artigos e documentos para que o pesquisador tome conhecimento e analise as contribuições científicas, de acordo com o tema em questão, a partir dos elementos que se constituem significativos para o pesquisador. Dessa forma, a mesma se apropriou dos métodos de pesquisa qualitativa com análise e discussão, pois, essa análise se apoiou em leitura, reflexão, diálogo e uma posição vasta no que esteve a discutir. Assim, para subsidiar essas escolhas metodológicas foram adotadas algumas técnicas específicas para a realização das atividades de pesquisa.

Inicialmente, foi feito um levantamento bibliográfico, onde houve uma análise das referências dos autores que discutem sobre o tema estudado. Em seguida, iniciou-se um diálogo com os mesmos, sobre a importância do saber da formação profissional para o ensino na educação básica e os desafios do ser docente e discutiu-se também sobre as concepções de autores na área de Matemática a respeito dos entraves para a contextualização dos conteúdos escolares com a realidade dos educandos.

E seguido a esse momento, buscou-se relatar o quanto a relação do saber cotidiano com o saber escolar é importante para o processo de ensino e aprendizagem em Matemática na educação básica. Em seguida, apresentou-se algumas contribuições para este processo, baseadas na contextualização do saber cotidiano com o saber escolar (abstrato e concreto). E em um último momento, foi feita uma sistematização dos resultados e considerações da pesquisa, na qual foi finalizada com a construção de uma reflexão sobre as problemáticas de acordo com os objetivos.

Outra questão é que a metodologia da pesquisa é o caminho essencial para a construção do conhecimento científico. Nesse sentido, descrevem-se os caminhos percorridos no desenvolvimento da pesquisa para alcançar o objetivo proposto no 
estudo. O caminho a ser seguido na pesquisa é determinado em função das hipóteses levantadas pelo pesquisador. Essas hipóteses serão analisadas, comprovadas ou não e, suscitarão outras hipóteses, é um trabalho contínuo de descobertas.

Como nos alertou Certeau (2002, p. 34) não se pode esquecer de que uma leitura do passado, por mais controlada que seja pela análise dos documentos, é sempre dirigida por uma leitura do presente. Sendo assim, as hipóteses serão implícitas e inevitáveis à qualquer modalidade de pesquisa.

Desse modo a presente pesquisa é resultado de uma revisão de literatura que procurou entender a relação entre a matemática e a sua utilização no cotidiano, e sua importância para uma educação consciente e problematizada frente às mudanças atuais. Dessa forma, realizam-se a utilização de fontes primarias onde o primeiro passo consistiu em selecionar na literatura artigos científicos que tivessem relação com a proposta a ser analisada, que resultou nas análises de cerca de 30 artigos científicos na plataforma Scielo, sendo que foram selecionados 11 para dar embasamento ao estudo.

\section{O Elo entre os Conteúdos Matemáticos e o Conhecimento Prévio do Aluno é Condição para uma Aprendizagem Significativa}

"Sabemos que todo grupo de pessoas, seja étnico, familiar, escolar, religioso ou empresarial possui seus valores, expectativas, preferências, objetivos e linguagem que o caracteriza, mas que se altera no tempo e no espaço" (Lorenzato, 2010, p. 21). E quando se pensa no grupo escolar, Freire (1996, p. 30) afirma que, "ensinar exige respeito aos saberes dos educandos. Por isso, coloca ao professor ou, mais amplamente, à escola, o dever de não só respeitar os saberes com que os educandos, sobretudo os das classes populares chegam a ela, saberes socialmente construídos na prática comunitária".

Assim, as noções matemáticas são construídas a partir de experiências proporcionadas pelas interações com o meio, pelo intercâmbio com outras pessoas que possuam interesses, conhecimentos e necessidades que podem ser compartilhadas. Então, "Por que não aproveitar as experiências que tem os alunos de viver [...]? Por que não discutir com os alunos a realidade concreta a que se deva associar a disciplina cujo conteúdo se ensina $[\ldots .$.$] ? Por que não estabelecer uma "intimidade" entre os$ saberes curriculares fundamental aos alunos e a experiência social que eles têm como indivíduo" (Freire, 1996, p. 30)? "Antes de atingir a idade escolar as crianças naturalmente vivem situações de contar, juntar, tirar, medir, distribuir, repartir, e lidam com diferentes formas geométricas. Assim, toda criança chega à escola com um saber vivenciado e diferente do ensinado pela escola" (Lorenzato, 2010, p. 24). Nesse sentido, Gauthier (2010), afirma que:

[...] quem ensina sabe muito bem que para ensinar, é preciso muito mais que simplesmente conhecer a matéria, mesmo que esse conhecimento seja fundamental. [...] pensar que ensina consiste apenas em transmitir um conteúdo a um grupo de alunos, é reduzir uma atividade tão complexa quanto o ensino a uma única dimensão. [...] Numa palavra, o saber do "magister" não se resume apenas ao conhecimento da matéria (Gauthier, 1998, p. 36).

E, nessa mesma linha de pensamento, Lorenzato (2010) insiste em dizer que:

Dar aulas é diferente de ensinar. Ensinar é dar condições para que o aluno construa seu próprio conhecimento. Vale salientar de que há ensino quando, em decorrência dele houve aprendizagem. Note que é possível dar aulas sem conhecer, entretanto, não é possível ensinar sem conhecer (Lorenzato, 2010, p. 01).

Esses conhecimentos sobre a importância individual de cada ser envolvido no processo de aprendizagem já estão bem estabelecidos nos Parâmetros Curriculares Nacionais - PCNs (Brasil, 1998), quando afirmam que a aprendizagem acontece pela interação professor, estudante e conhecimento. E propõem que o professor seja um mediador entre os conhecimentos 
científicos e a ideia prévia dos estudantes; nesse sentido, Ribeiro (1997, p. 100) argumenta que "o ponto de partida para a aquisição dos conteúdos matemáticos deve ser os conhecimentos prévios dos educandos".

E quando se trata do professor e seu envolvimento no ensino e aprendizagem, percebe-se que em alguns casos as formações continuadas ofertadas aos professores são, por vezes, generalizantes e superficiais, instruindo o docente para ser um aplicador de técnicas e não um profissional no sentido de ter um domínio amplo sobre sua prática com segurança suficiente para tomar decisões que viabilizem aperfeiçoar seu trabalho sem depender totalmente de certos instrumentos de auxílio como, por exemplo, os livros didáticos, entre outros. Nesse sentido, Franchi (1995) afirma que:

O professor deve ter a [sic] sua disposição um conhecimento que ilumine a sua ação. Este não pode se limitar a conteúdos e instrumentos com que trabalhará em sala de aula. Em termos mais simples: o professor não deve saber apenas o que vai ensinar como se a qualidade das suas aulas dependesse de "cópia-xérox" do ensino que aprendeu. Ao contrário, a qualidade de ensino depende de um sistema de conhecimento muito mais amplo, para que o professor possa entender melhor o que dá sentido em função do que ensina (Franchi, 1995, p. 66).

Assim, Nogueira et al. (2014, p. 139) afirmam que as dificuldades escolares de alunos relacionadas à aprendizagem da Matemática podem ser atribuídas a diferentes variáveis, entre as quais, as possibilidades de que a atuação do professor seja influenciada por sua formação inicial e continuada. A partir da afirmação de Nogueira, verifica-se que o professor deve ser sempre dinâmico, aprimorando cada vez mais a prática com a inserção de cursos, como a formação continuada e pósgraduação, o que contribui para possíveis mudanças em metodologias de ensino, possibilitando a redução das dificuldades de aprendizagem dos alunos que necessitam de motivação com aulas que o chamem a atenção.

A publicação dos PCNs (Brasil, 1998) representa um esforço de colaborar na melhoria da qualidade do ensino. No que se refere à Matemática, abordam sua importância desta área do conhecimento no cotidiano, permitindo a solução de problemas e auxiliando na elaboração de conhecimentos em outras áreas. A constatação de que o ensino tem valorizado “(...) procedimentos mecânicos, desprovidos de significados para o aluno revela a urgência de se reformular objetivos, rever conteúdos e buscar metodologias compatíveis com a realidade" (Brasil, 1998, p. 15). Segundo Andrade (2013):

Muitas são as reclamações acerca do modelo atual do ensino da matemática e frisa-se bastante a questão de que a matemática da escola é descontextualizada da utilizada na vida prática do aluno e assim, essa realidade do ensino da matemática, torna as aulas pouco atrativas e o aluno não sente necessidade de aprender tal matéria, que para ele é desvinculada da sua vida cotidiana, justificando assim uma pesquisa sobre tal situação à busca de encontrar sugestões para a melhoria dessa situação (Andrade, 2013, p. 11).

O professor tem a função de facilitar a aprendizagem, porém, a sua didática pode transformá-lo em um obstáculo para o mesmo, pois o modo como tem trabalhado os conteúdos não tem levado os alunos a desenvolver a capacidade de reflexão em relação àquilo que está sendo ensinado.

Quando se observa uma sala de aula percebe-se que o texto dos PCN's não condiz com a realidade do ambiente escolar, onde a matemática e a vida do aluno não estão caminhando juntos. Porém, essa situação deve ser repensada, de modo a associar a teoria com a prática, pois isso possibilita ao aluno uma aprendizagem mais significativa (Andrade, 2013, p. 17).

O ensino da Matemática, quando parte do conhecimento que o aluno já dispõe, possibilita ao mesmo conhecer e investigar com mais profundidade e amplitude os conhecimentos que fazem parte de sua realidade: a construção de conhecimentos matemáticos não deve ser um simples repasse de informações contidas nos livros didáticos. Partindo destes pressupostos, percebe-se que a valorização dos conhecimentos prévios dos alunos, uma vez relacionados com os conteúdos da 
escola ministrados pelos docentes, terá, com isto, uma maior participação dos mesmos na resolução de situações-problemas do cotidiano.

Não há no presente trabalho a pretensão de modificar nenhum conteúdo ou programa matemático, mas sim contribuir para que a Matemática fique o mais próximo possível da necessidade dos alunos. "Assim o professor desenvolve uma relação, um vínculo de cumplicidade com seu aluno que facilitará a construção de conhecimentos significativos" (Imenes \& Lellis, 1997, p. 13). A aprendizagem é muito mais significativa à medida que o novo conteúdo é incorporado às estruturas de conhecimento de um aluno a partir da relação com seu conhecimento prévio, ao contrário, ela se torna mecânica ou repetitiva.

\section{Formação Profissional e o Desafio de ser Docente}

A formação profissional, Segundo Goes e Pilatti $(2012$, p. 20) "trata de métodos de ensino para adultos que visam facilitar a aprendizagem". Nesse sentido, é a preparação e emancipação do docente para realizar crítica reflexiva e eficazmente um estilo de ensino que promova uma aprendizagem significativa nos alunos e consiga um pensamento inovador resumido em um processo contínuo de aprender para ensinar.

A formação de professores, designada como formação inicial, ocorre no ensino superior e é orientada pela Lei de Diretrizes e Bases da Educação - LDB, Lei 9394/96 (Brasil, 1996), destacado no Capítulo IV, artigo 43, como finalidade:

I - estimular a criação cultural e o desenvolvimento do espírito científico e do pensamento reflexivo; II - formar diplomados nas diferentes áreas de conhecimento, aptos para a inserção em setores profissionais e para a participação no desenvolvimento da sociedade brasileira, e colaborar na sua formação contínua; III - incentivar o trabalho de pesquisa e investigação científica, visando o desenvolvimento da ciência e da tecnologia e da criação e difusão da cultura, e, desse modo, desenvolver o entendimento do homem e do meio em que vive (Brasil, 1996, p. 32).

Portanto, o objetivo da formação profissional perpassa desde o preparo do profissional, bem como a sua formação contínua ao espírito científico e reflexivo para que este entenda e atue na sociedade, no meio em que vive. No entanto, a formação da maioria dos professores está centrada apenas no paradigma da centralidade técnica, que, segundo Pérez (1995, citado em Nóvoa, 1997, p. 79), “é uma concepção epistemológica da prática herdada do positivismo na qual a atividade profissional e instrumental é dirigida para a solução de problemas, mediante as aplicações rigorosas de teorias e técnicas cientificas".

O professor dinâmico deve ser um coparticipante do seu processo de formação, pois não deve estagnar-se enquanto a ciência avança para outros patamares e com grandes escalas em inúmeras tecnologias. Assim, a continuidade de formação se torna essencial e, em relação a este ponto, o artigo 61 da LDB (Brasil, 1996) apresenta os fundamentos dessa formação para atender aos objetivos dos diferentes níveis e modalidades de ensino e as características de cada fase do educando, futuro professor:

I - A associação entre teoria e prática, inclusive a capacitação em serviço;

II - Aproveitamento da formação e experiências anteriores, em instituição de ensino e outras atividades do cotidiano.

Portanto, baseando-se na LDB, percebe-se a importância das instituições formadoras de professores estarem abertas à inclusão de metodologias que podem vincular-se a partir de uma associação entre teoria e prática considerando as experiências do educando para formar profissionais que terão a missão de educar e preparar para o exercício da cidadania, o que pode ser verificado nos PCNs de Matemática de Ensino Fundamental onde relata que:

Para desempenhar seu papel de mediador entre o conhecimento matemático e o aluno, o professor precisa ter um sólido conhecimento dos conceitos e procedimentos dessa área e uma concepção de Matemática como ciência que não 
trata de verdades infalíveis e imutáveis, mas como ciência dinâmica, sempre aberta à incorporação de novos conhecimentos (Brasil, 1998, p. 36).

É preciso considerar que o professor, como protagonista da mediação de conhecimento vinculado aos conteúdos ministrados, precisa ter domínio de tudo que irá desenvolver no processo de ensino e aprendizagem, onde, sem dúvida, serão de grande importância sua formação inicial e continuada como elementos essenciais para proporcionar aos estudantes melhor compreensão dos conteúdos ministrados. Em relação a conteúdos a serem ensinados, com o saber do discente, Freire mostra que:

A formação dos professores e das professoras devia insistir na constituição deste saber necessário (...) que é a importância inegável que tem sobre nós o contorno em que vivemos. E ao saber teórico desta influencia teríamos que juntar o saber teórico-prático da realidade concreta em que os professores trabalham (Freire, 1996, p. 137).

Portanto, desempenhar a função de professor tem sido um grande desafio para os recém-formados. Pois, "muito do que o professor sabe ou precisa saber para bem desempenhar sua função, ele não aprende nos cursos de formação de professor" (Lorenzato, 2010, p. 09). Ele aprende a partir da sua prática docente. Assim, a formação profissional de professores pouco tem contribuído com a temática de relacionar o Saber Cotidiano (constituí um conhecimento utilizado nas práticas diárias, sendo mediado e atualizado pela "necessidade" que a vivência cotidiana requisita (Pelaes, 2010)) com o Saber Escolar (é identificado com um tipo de conhecimento institucionalizado e legitimado, que tem sua validade proporcional às categorias do contexto em que foi estabelecido, porém refletindo o conceito de conhecimento científico, apresentando as noções de unicidade e de universalidade (Pelaes, 2010)) no ensino da Matemática, pois o motivo é o pouco incentivo dado ao futuro docente para a pesquisa, principalmente a pesquisa de campo, pois, além da reflexão e atualização da formação, é importante a interação do professor com a pesquisa. De acordo com Lorenzato (2010).

Talvez essa condição de que o professor deve ser um pesquisador, [sic] seja tão ideal quanto utópica ante a nossa realidade. Para tornar-se um pesquisador é preciso aprender a fazer pesquisa, o que só ocorre em cursos de mestrados e doutorados. Apesar de haver grande interesse por parte dos professores (Lorenzato, 2010, p. 127).

E com isso, se torna uma tarefa difícil contribuir com uma aprendizagem que tenha significado para o aluno, o que dificulta a formação de um profissional reflexivo, sendo, por tanto, um desafio para os novos professores relacionar em sua prática docente os conteúdos escolares com os saberes do educando (Freire, 1996, p. 39).

Refletir a prática na formação inicial e continuada do professor é o primeiro passo para vencer os desafios da educação e deve ser vista como uma necessidade de mudança do paradigma de ensino, de um modelo passivo, para um modelo baseado no desenvolvimento de competências que atendam às necessidades dos alunos segundo consta nos PCNs. E assim, será possível vencer o grande desafio encontrado pelos professores em relacionar os conteúdos escolares com a realidade dos educandos para a produção de conhecimento no processo educativo da educação básica.

\section{Os Entraves para a Contextualização dos Conteúdos Escolares com a Realidade dos Educandos}

Nos últimos tempos, em decorrência de crise política, que tem acarretado mudanças sociais, econômicas e culturais, o mundo todo tem sido impactado, sendo a educação um dos principais alvos destas mudanças, especialmente a que se desenvolve nos sistemas das escolas públicas, e educar tem se tornado uma tarefa cada vez mais exigente e de enorme responsabilidade. Isso requer equilíbrio e coerência entre orientação formativa e procedimentos pedagógicos adaptados a expectativas dos educandos trazendo o conteúdo a ser ensinado para próximo da realidade em que o aluno vive. 
Desempenhar essa tarefa com compromisso e qualidade exige do professor reunir um conjunto de saberes e competências que lhe permitam a construção de um ensino de qualidade. Na ótica de Tardif (2008, p. 16), o saber docente "relaciona-se com a pessoa, com a sua identidade, com a sua experiência de vida, com a sua história profissional, com as suas relações com os alunos na sala de aula e com os outros". Assim, os saberes do professor são construídos ao longo de toda uma carreira e vida do mesmo, e são apropriados pelo professor, também, através da formação continuada, cuja construção intervém dimensões identitárias, de socialização profissional, fases e mudanças, que se constituem num conjunto de conhecimentos, competências, habilidades e atitudes.

Porém é possível perceber que a relação estabelecida entre o saber cotidiano e o saber escolar não está sendo valorizada ou revitalizada nos cursos de formação de professores, ainda que esta relação seja importante para a geração de um processo de conhecimento integrado e complexo, que transcende às categorias que a escola institui.

"Por sua vez a principal variável que influencia as possibilidades de atuação do professor é a sua formação inicial e continuada" (Nogueira et al., 2014, p. 15). Esta lacuna tem se destacado como um entrave no que diz respeito a contextualização dos conteúdos escolares com a realidade dos educandos, impossibilitando os futuros professores de realizar tais procedimentos. E com isso, o saber cotidiano é entendido, nessa relação, dentro do universo escolar, como um conhecimento associado somente às práticas diárias, próprias de cada indivíduo e fora do contexto escolar.

Já o saber escolar é valorizado dentro do universo escolar, como sendo o conhecimento legítimo que lhes confere direitos de cidadania. Esse conhecimento legítimo, ou visto como tal, tem seu aporte apenas no conhecimento científico. Nessa ótica, a escola passa a desconhecer aquela orientação dos PCNs em que: "tal disposição de conhecimentos prévios deve ser inserida nas práticas escolares" (Brasil, 1998, p. 59). Fazendo com que as dificuldades no ensino e aprendizagem de matemática continuem sendo um dos maiores problemas da educação básica.

De acordo com D'Ambrósio (2006, p. 18), “um dos grandes desafios para a formação de professores que ensinam Matemática é promover práticas educativas integradas às ideias matemáticas, às diversas culturas e ao mundo moderno". Neste contexto, percebe-se que a formação inicial e continuada não está dando possibilidade ao futuro professor de privilegiar a contextualização e ter como preocupação produzir uma aprendizagem considerável, valorizando o conhecimento espontâneo do discente, de maneira que ele supere a condição de espectador. Pois, a contextualização do currículo é fundamental para motivar os alunos. Se os professores não conseguirem trazer para sala de aula situações que permitam ao aluno se identificar, não conseguirão uma interação maior em sala de aula.

A escola deve contribuir para a formação do aluno crítico e reflexivo frente à realidade em que vive, caso contrário, o professor precisa não só avaliar o aluno, mas refletir sua prática para não cometer erros de apontar todas as dificuldades como sendo exclusivas do aluno. De acordo com Nogueira et al. (2014):

No decorrer desses anos observamos que muitos professores apontavam dificuldades que descreviam como sendo de seus alunos, mas que nós percebíamos serem também deles, o que indicava que suas carências não se restringiam ao conhecimento didático-pedagógico, abrangiam também os conteúdos propriamente ditos (Nogueira et al., 2014, p. $15)$.

Por certo, não basta ao professor o conhecimento do conteúdo a ser ensinado para efetividade de sua ação pedagógica. Estudos atuais sobre os conhecimentos necessários ao professor para uma atuação eficaz em sala de aula, como o de Tardif (2002) e Franchi (1995), têm enfatizado que o conteúdo é uma condição básica para a docência nos diferentes níveis de ensino, mas apenas o conteúdo não é suficiente para se obter uma aprendizagem que tenha significado para o educando.

Portanto, a falta de capacitação dos futuros professores tem sido o maior entrave para a contextualização dos conteúdos escolares com realidade do educando e isso se deve à formação profissional e continuada, que muitas vezes é pautada apenas dentro das quatro paredes da sala de aula, deixando o futuro professor sem a possibilidade de antes de atuar 
como profissional, conhecer a diversidade de saberes dos alunos e o contexto histórico em que a comunidade escolar está inserida. Isso dificulta não só a prática de relacionar os conteúdos a ser ensinados na escola com a vivência do dia-a-dia do aluno, mas, desconhece também, a importância da relação do saber escolar com o saber cotidiano para o ensino e a aprendizagem significativa do educando.

\section{O Ensino e Aprendizagem da Matemática e a Importância da Relação do Saber Escolar com o} Saber Cotidiano para o Educando

Ao analisar o atual modelo de formação profissional e suas práticas utilizadas no processo de ensino e aprendizagem de Matemática, com destaque especial para a importância da relação entre o saber escolar e o saber cotidiano do educando, pode-se evidenciar que o atual modelo educacional no Brasil não capacita os educandos para a tomada de decisão e para a participação ativa e consciente na sociedade.

O ensino e aprendizagem de Matemática, por sua vez, corroboram com esta visão, não proporcionando uma aprendizagem significativa e perspicaz que possibilite o pleno exercício da cidadania. A Matemática tem sido frequentemente eleita como a grande causadora de "fobia escolar". Assim, esta disciplina foi privilegiada devido a mesma ainda ser vista como ideia geral de que é uma disciplina difícil e que o tema envolve somente números, equações, álgebras, problemas; enfim, criando certo tipo de preconceito, afirmando que só aprende matemática quem é muito inteligente. Porém essa visão é extremamente empobrecida e não representa a disciplina em si.

É possível perceber que esse fracasso na aprendizagem é demandado pelas dificuldades do ensino dos professores, reflexo de uma formação limitada a métodos tradicionais, esquecendo que antes de ensinar é preciso conhecer o sujeito do aprendizado. De acordo com Lorenzato (2010, p. 14), "não é lógico nos atermos ao que, como, porque e quando ensinar sem procurar conhecer a quem ensinar". Tal método contribui para o esquecimento de que o conhecimento que o aluno traz do seu cotidiano não pode ser ignorado e sim relacionado com o saber escolar, pois os dois se complementam.

"Sabemos também, que o ensino da matemática, para ser proveitoso ao aluno, precisa estar vinculado à realidade na qual este está inserido" (Lorenzato, 2010, p. 21). Para tanto, o ensino da Matemática precisa ser planejado e ministrado tendo em vista a complexa identidade de seus alunos. "Por que não discutir a realidade concreta a que se deva associar a disciplina cujo conteúdo se ensina ...?” (Freire, 1996, p. 30). Assim, os PCNs de Matemática do ensino fundamental também enfatizam a importância de relacionar o saber cotidiano dos alunos com o saber escolar para uma aprendizagem com melhores resultados.

As necessidades cotidianas fazem com que os alunos desenvolvam capacidades de natureza prática para lidar com a atividade matemática, o que lhes permite reconhecer problemas, buscar e selecionar informações, tomar decisões. Quando essa capacidade é potencializada pela escola, a aprendizagem apresenta melhor resultado (Brasil, 1998, p. 37).

O texto dos PCNs nos leva a ter certeza de que a matemática escolar e a vida cotidiana do aluno podem, sim, caminhar juntas, de modo que o professor possa associar a teoria com a prática e essa relação é de grande importância para o desenvolvimento de uma aprendizagem significativa.

Portanto, o ensino da matemática está diretamente ligado ao cotidiano dos educandos já que as primeiras noções matemáticas são construídas a partir da sua vivencia, e tanto no trabalho, quanto no espaço onde interagem, a matemática se faz presente. Nesse sentido, relacionar teoria e prática é fundamental para que o aluno compreenda efetivamente os conteúdos matemáticos, pois, "abordados de forma isolada, eles não se tornam uma ferramenta eficaz para resolver problemas e para a construção de novos conceitos" (Brasil, 1998, p. 37). Assim, a relação do saber escolar com o saber cotidiano se torna não só importante, mas necessário para o ensino e aprendizagem em matemática. 


\section{Contribuições para o Ensino e Aprendizagem em Matemática: Do Concreto ao Abstrato}

A formação de professores que ensinam matemática está no centro de discussões em diferentes fóruns de pesquisadores. Em eventos como o Encontro Nacional de Educação Matemática (ENEM), o Seminário Internacional de Pesquisa em Educação Matemática (SIPEM), Semana da Matemática (SEMAT), entre outros.

Esta temática vem se constituindo em uma das áreas mais investigadas na educação matemática devido à importância que tem para os saberes docentes, porém, ainda com muitas questões em aberto. Uma delas tem sido central nas discussões: não se pode conceber uma formação inicial ou continuada, sem levar em consideração o conteúdo matemático necessário para se garantir um ensino bem fundamentado nos aspectos teóricos e conceituais do ensino de Matemática, mas apenas isso não é suficiente. Assim, as aulas não serão mais um elenco de conteúdos e na sua maioria desinteressantes, inúteis e desconectados da realidade dos alunos.

Portanto, é necessário que sejam incluídos na diversidade do processo de formação inicial dos professores de Matemática a discussão sobre a importância da relação entre o saber cotidiano e o saber escolar no ensino da Matemática, onde tais processos envolvem a formação de saberes docentes necessários para a prática profissional em sala de aula, visto que o ensino da Matemática tem sido um desafio não só para os professores na sua missão de ensinar, mas também para o aluno na sua responsabilidade e capacidade de aprender. O problema não está no fato dos estudantes não conseguirem usar a matemática, na verdade eles não conseguem usar a matemática escolar por a verem apenas como algo abstrato, "as pessoas precisam pegar para ver, como dizem as crianças. Então, não começar o ensino pelo concreto é ir contra a natureza humana. Quem sabe ensinar sabe disso" (Lorenzato, 2010, p. 19).

Neste contexto, as evidências nos mostram que se quisermos aumentar a habilidade de aprender a disciplina, precisamos avaliar a forma e o contexto no que ela é apresentada e trazer o conteúdo a ser ensinado para próximo da realidade do educando, ou seja, apresentar os conteúdos relacionando com objetos presentes no meio em que o aluno interage, objetos que o aluno se relaciona e tem domínio sobre o mesmo, pois de acordo com Lorenzato (2010, p. 17) " palavras não alcançam o mesmo efeito que conseguem os objetos ou imagens, estáticos ou em movimento. Palavras auxiliam, mas não são suficientes para ensinar" (Lorenzato, 2010, p. 17). E continua dizendo que "não começar o ensino pelo concreto é ir contra a natureza humana" (Lorenzato, 2008, p. 19). Em outras palavras, o autor menciona que a aprendizagem se torna mais significativa e facilitadora quando se começa pelo fazer seguido pelo ver, ou seja, do concreto para o abstrato.

Após estudos e discussões da temática em questão, há a necessidade de apontar contribuições que venham solucionar ou amenizar tal problema levantado. Pois, através deste estudo ficou evidente que não basta conhecer teorias, é preciso ser capaz de propor e executar soluções adequadas às contingências do seu labor cotidiano. Isso transcende a capacidade de mobilização e articulação de conhecimentos teóricos, é necessário que o professor desenvolva a capacidade de lidar com situações concretas. "Na verdade, assim como é preciso abrir mão do rigor para se conseguir o rigor, para se alcançar a abstração é preciso começar pelo concreto. Este é o caminho para a formação de conceitos” (Lorenzato, 2010, p. 20).

Neste sentido, aqui são sugeridas algumas contribuições baseadas na obra "Para aprender Matemática", de Sérgio Lorenzato, na tentativa de contribuir para que o ensino e aprendizagem de Matemática se tornem significativo tanto para quem aprende quanto para quem ensina, derrubando aquela velha ideia de que a matemática é só para os inteligentes. Portanto abaixo seguem vinte conselhos para os bons profissionais que desejam ensinar com qualidade:

1) Ensinar com conhecimento; 2) Analisar a moda; 3) Valorizar a experiência do magistério; 4) Investir em sua formação; 5) Auscultar o aluno; 6) Começar pelo concreto; 7) Considerar o contexto grupal; 8) Aproveitar a vivencia do aluno; 9) Respeitar a individualidade do aluno; 10) Partir de onde o aluno está; 11) Tomar cuidado com o simples, o óbvio e o acerto; 12) Atentar para a linguagem matemática; 13) Valorizar os erros do aluno; 14) Interpretar a matemática como instrumento; 15) 
Explorar as aplicações matemáticas; 16) Proporcionar experimentação; 17) Favorecer a descoberta; 18) Enfatizar os porquês matemáticos; 19) Assumir melhor postura profissional e; 20) Pensar no que faltou.

Os apontamentos aqui sugeridos, baseados em Lorenzato (2010), de um lado permitem flexibilidade didática ao professor, por outro, recomenda alguns princípios a serem seguidos antes, durante e depois das aulas. Assim, do ponto de vista do ensino da matemática, esses princípios serão analisados e exemplificados com o objetivo de tornar o ensino mais compreensível, simples e agradável aos alunos.

\section{Considerações Finais}

A proposta de um novo conhecimento escolar integrado, relacionando o conhecimento cotidiano com o conhecimento científico, oferece aos educadores espaço para buscar os caminhos da valorização da docência e da identificação da qualidade da educação escolar. A aprendizagem qualitativa pode encontrar neste conhecimento a sustentação que lhe é fundamental. Embora esta proposta já tenha sido mencionada há muito tempo pelos PCNs, ainda não é colocada plenamente em pratica, sendo ignorada principalmente nos cursos de formação inicial e continuada para professores.

A formação profissional de professores pouco contribui em formar profissionais pesquisadores que estejam ligados às questões sociais, culturais e econômicas, por isso, ser docente tem sido um grande desafio nos dias atuais. Ser docente hoje exige um conjunto de saber a ponto de contextualizar o conteúdo escolar com o cotidiano do aluno, preparando o educando não só para passar nas provas, mas para ser cidadão apto para a atuação consciente e responsável na sociedade. Porém, o saber o qual os professores geralmente trabalham atualmente está sustentado nos livros didáticos e nos programas escolares, reflexos de uma formação pautada somente em sala de aula.

Relacionar o saber escolar com o saber cotidiano do aluno é de grande relevância para o ensino e aprendizagem em matemática na educação básica, pois a matemática está diretamente ligada às tarefas diárias do educando e desvincular a matemática do cotidiano da matemática escolar é negar as possibilidades de proporcionar ao aluno uma aprendizagem reflexiva, significativa e de qualidade. Tendo em conta estes aspetos, ainda se acredita numa formação inicial que possibilite os professores a lutar pelo desenvolvimento de uma metodologia formativa que esteja adequada a cada contexto e a cada sujeito.

Portanto, espera-se, assim, que este trabalho possa contribuir de forma reflexiva para a compreensão do significado de contextualização dos conteúdos escolares com a realidade dos educandos, e a importância da sua utilização para uma aprendizagem mais significativa.

\section{Referências}

Andrade, C. C. (2013). O Ensino da Matemática para o cotidiano. Ed. Medianeira.

Brasil. (1996). Lei n. 9.394, de 20 de dezembro de 1996. Estabelece as diretrizes e bases da educação nacional. República Federativa do Brasil

Brasil. (1998). Parâmetros Curriculares Nacionais para o Ensino Médio (PCNs). Secretaria de Educação Fundamental. MEC/SEF.

Charlot, B. (2000). Da relação com o saber. Ed. Artes Médicas.

Cunha, M. I. (2005). O professor universitário na transição de paradigmas. JM Editora.

Certeau, Michel de. (2002) A escrita da História. Rio de Janeiro: Forense Universitária, 2 ed

D’Ambrósio, U. (2006) Formação de professores de matemática: Professor-pesquisador. Atos de pesquisa em Educação, 1(1), 75-85.

Imenes, L. M., \& Lellis, M. (1997). Matemática. Scipione. 
Research, Society and Development, v. 11, n. 2, e51511225853, 2022

(CC BY 4.0) | ISSN 2525-3409 | DOI: http://dx.doi.org/10.33448/rsd-v11i2.25853

Franchi, E. P. (1995). A insatisfação dos professores: consequências para a profissionalização. In Franchi, E. P. (org.) A causa dos professores. Campinas: Papirus.

Freire, P. (1996). Pedagogia da autonomia: Saberes necessários à prática educativa. Paz e Terra. (Coleção Leitura).

Gauthier, C. (1998). Por uma teoria da Pedagogia - Pesquisas Contemporâneas sobre o Saber Docente. Ijuí: UNIJUí.

Goes, P. B. \& Pilatti, L. A. (2012). Formação profissional e competências: elementos para uma reflexão andragógica. Revista Eletronica FAFIT/FACIC, 3(2), $15-34$.

Lorenzato, S (2010). Para aprender matemática. (3a ed.), Autores Associados.

Machado, N. J. (2009). Matemática e Realidade. (7a ed.), Cortez.

Marconi, M. de A., \& LAKATOS, E. M. (003). Fundamentos da Metodologia Científica. (3a ed.), Atlas.

Melo, G. F. A. (1998). Saberes Docentes de Professores de Matemática em um Contexto de Inovação Curricular (Dissertação de Mestrado). Universidade Estadual de Campinas - UNICAMP, Campinas, São Paulo, Brasil.

Nogueira, C. M. I., Pavanello, R. M. \& de Oliveira, L. A. (2014). Uma experiência de formação continuada de professores licenciados sobre a matemática dos anos iniciais do ensino fundamental. Revista Paranaense de Educação Matemática (RPEM), 3(4), 138-160.

Pelaes, M. L. W. (2010). Uma reflexão sobre as relações entre o saber cotidiano e o saber escolar, no ensino de matemática. Webartigos. https://www.webartigos.com/artigos/uma-reflexao-sobre-as-relacoes-entre-osaber-cotidiano-e-o-saber-escolar-no-ensino-de-matematica/50571.

Pérez G, A. (1997). O pensamento prático do professor: a formação do professor como profissional reflexivo. In A. Nóvoa, (Org.), Os professores e sua formação (3a ed., pp. 93-114). Dom Quixote.

Pimenta, S. G. (Org.). (1999). Saberes pedagógicos e atividade docente. Cortez.

Ribeiro, V. M. (coord.). (1997). Educação de jovens e adultos: Proposta curricular para o primeiro segmento do ensino fundamental. São Paulo: Ação Educativa / Brasília: MEC.

Silva, M. B., \& Schappo, V. L. (2002) Introdução à pesquisa em educação. UDESC.

Tardif, M. (2002). Saberes Docentes e Formação Profissional. Vozes. 